\title{
Endoscopic ultrasound efficacy in staging gastric linitis plastica lesion: a retrospective multicentric French study
}

\author{
Stephanie Morgant ${ }^{1}$, Pascal Artru ${ }^{2}$, Ammar Oudjit ${ }^{3}$, Nelson Lourenco ${ }^{4}$, Arnaud Pasquer ${ }^{5}$, \\ Thomas Walter ${ }^{6}$, Jean-Marc Gornet ${ }^{4}$, Alexandre Rouquette ${ }^{7}$, Catherine Brezault ${ }^{1}$, Romain Coriat $^{1}$ \\ ${ }^{1}$ Gastroenterology and digestive oncology unit, Hôpital Cochin, Paris, France; ${ }^{2}$ Gastroenterology and Digestive Unit, Jean Mermoz Clinic, Lyon, \\ France; ${ }^{3}$ Radiology Unit, Cochin Teaching Hospital, Paris, France; ${ }^{4}$ Gastroenterology Unit, Saint-Louis Teaching Hospital, Paris, France; ${ }^{5}$ Digestive \\ Surgery Unit, Edouard Herriot Teaching Hospital, Lyon, France; ${ }^{6}$ Oncology Unit, Edouard Herriot Teaching Hospital, Lyon, France; ${ }^{7}$ Pathology \\ Department, Cochin University Hospital, Paris, France \\ Contributions: (I) Conception and design: All authors; (II) Administrative support: S Morgant, R Coriat; (III) Provision of study materials or patients: \\ All authors; (IV) Collection and assembly of data: S Morgant; (V) Data analysis and interpretation: S Morgant, R Coriat; (VI) Manuscript writing: All \\ authors; (VII) Final approval of manuscript: All authors. \\ Correspondence to: Prof. Romain Coriat, MD, PhD. Service de gastroenterologie et d'oncologie digestive, CHU Cochin, 27 rue du faubourg saint \\ Jacques, 75014 Paris, France. Email: Romain.coriat@aphp.fr; romain.coriat@aphp.fr.
}

\begin{abstract}
Background: Endoscopic ultrasound (EUS) is a key imaging technique in gastric cancer (GC). The aim of this study was to evaluate the performance of EUS in the staging of parietal and lymph node involvement in linitis plastica (LP) compared to "classical" GC.

Methods: A retrospective multicentric French study was conducted on patients with no metastatic LP and operated by gastrectomy. A 2/1 matching based on pTNM stage and center was performed with GC.

Results: Forty-three patients were included, sixteen patients in the LP group and 27 in the control group. Sensitivity and specificity of EUS for diagnosis of T3-T4 parietal invasion were $77 \%$ and $100 \%$ respectively in the LP group and $89 \%$ and $56 \%$ respectively in the control group. Sensitivity and specificity of EUS for diagnosis of lymph node involvement were $73 \%$ and $80 \%$, respectively in the LP group and $88 \%$ and $50 \%$, respectively in the control group. Patients from LP group had significantly more advanced histological lesion, and frequent undiagnosed peritoneal carcinomatosis.

Conclusions: This study evaluated for the first time in a European population, the preoperative EUS performance in LP. Our study identified a similar sensitivity and specificity of the EUS in LP compared to "classical" GC paving for a broader use of EUS in preoperative settings.
\end{abstract}

Keywords: Linitis plastica (LP); gastric cancer (GC); digestive cancer; endoscopic ultrasound (EUS); case-control study

Submitted Apr 21, 2020. Accepted for publication Sep 25, 2020.

doi: 10.21037/atm-20-3474

View this article at: http://dx.doi.org/10.21037/atm-20-3474

\section{Introduction}

Gastric adenocarcinoma is the $5^{\text {th }}$ most frequent cancer in the world with 951,000 new cases in 2012 (1). In the United States, 26,370 new cases and 10,730 deaths were reported for this cancer in 2015 (2). In France, 6,550 new cases per year and 4,410 deaths per year are related in 2012 (3), representing the $4^{\text {th }}$ cause of digestive cancer and the $4^{\text {th }}$ leading cause of cancer death.

The etymology of the "linitis" term comes from the aspect of the hypertrophic submucosal layer with irregular bands, taking the appearance of linen. William Brinton described it for the first time in 1859 (4). Linitis plastica (LP) is a distinct phenotype of gastric carcinoma, which includes both macroscopic and microscopic features. Macroscopically, LP is conventionally described as diffuse 

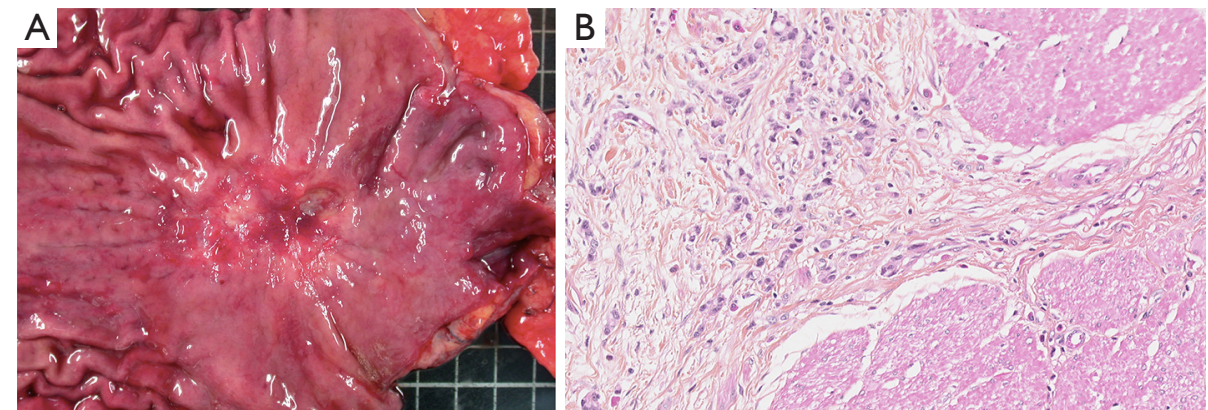

Figure 1 Gastric cancer. (A) Macroscopic aspect of linitis plastica with rigid large folds; (B) and microscopic aspect of linitis plastica with a dense desmoplastic reaction $(\mathrm{HE}, \times 200)$.

infiltration, frequently circumferential, involving more than $1 / 3$ of the stomach surface and most of the time the entire surface, causing thickening and stiffening of wall. Most of the time, mucosa is normal and without ulceration. Histologically, the main feature is a dense desmoplastic reaction in the submucosal and muscular layers of stomach (Figure 1). Cells are always poorly cohesive and often described as signet ring cells. Independent cells are isolated or arranged in small aggregates and characterised by the loss of adhesion capacity secondary to a somatic mutation of the $C D H 1$ gene coding for the E-cadherine membrane protein.

The initial assessment is a crucial step in the management of patients with gastric carcinoma because it determines treatment in localized forms (neoadjuvant chemotherapy, primary gastrectomy) (5-7). Computed tomography scan (CT scan) is an essential examination in the pretherapeutic assessment of gastric adenocarcinoma, including LP and is recommended by scientific societies (the European Society for Medical Oncology, ESMO and National Thesaurus of Digestive Oncology) $(5,6)$. In a previous study, we showed that computed-tomography scan has an equal sensitivity and specificity for the evaluation of lymph node and parietal involvement in classical gastric adenocarcinoma and in LP (8). Scientific societies recommended in case of LP to perform Endoscopic ultrasound (EUS).

Here, we performed a multicenter study to evaluate the performance of preoperative EUS in two different type of gastric adenocarcinomas: LP and "classical" gastric adenocarcinoma. We present the study in accordance with the STROBE reporting checklist (available at http://dx.doi. org/10.21037/atm-20-3474).

\section{Methods}

We conducted a retrospective multicentric French matched study on patients treated for gastric adenocarcinoma and operated. Inclusion period ranged from January 1, 2006 to December 31, 2015. Four centers participated in this study in France: Cochin University Hospital and Saint-Louis University Hospital in Paris, Edouard Herriot University Hospital and Jean Mermoz Clinic in Lyon. From the same database, the performance of the computed tomography scan was evaluated in gastric LP lesion (8). The inclusion criteria were as follows: aged $>18$ years, endoscopic diagnosis of LP with histological confirmation, absence of distant metastases, and total or partial gastrectomy with lymph node dissection. Total or partial gastrectomies performed for gastric adenocarcinoma over the aforementioned inclusion period were identified. Patients with a gastric LP diagnosis on histological report were included in the LP group. Patients with no available preoperative EUS were secondarily excluded. Patients were matched to the TNM stage and the center at the rate of two patients per case of LP. Two groups were established: the LP group and the control group. Pathological findings that did not conform to AJCC 2010 classification were reviewed in order to achieve harmonization of histological classifications $(8,9)$. The exclusion criteria were a history of gastric surgery, invasive endoscopic procedure on the stomach (mucosectomy, cystogastrostomy, digestive prostheses), esophago-gastric radiotherapy, Lynch's syndrom, germline CDH1 mutation, esophageal tumor (classified Siewert 1), mixed tumor with neuroendocrine contingent, association with gastric lymphoma, and preoperative EUS not available or not meeting the inclusion criteria listed earlier. The 


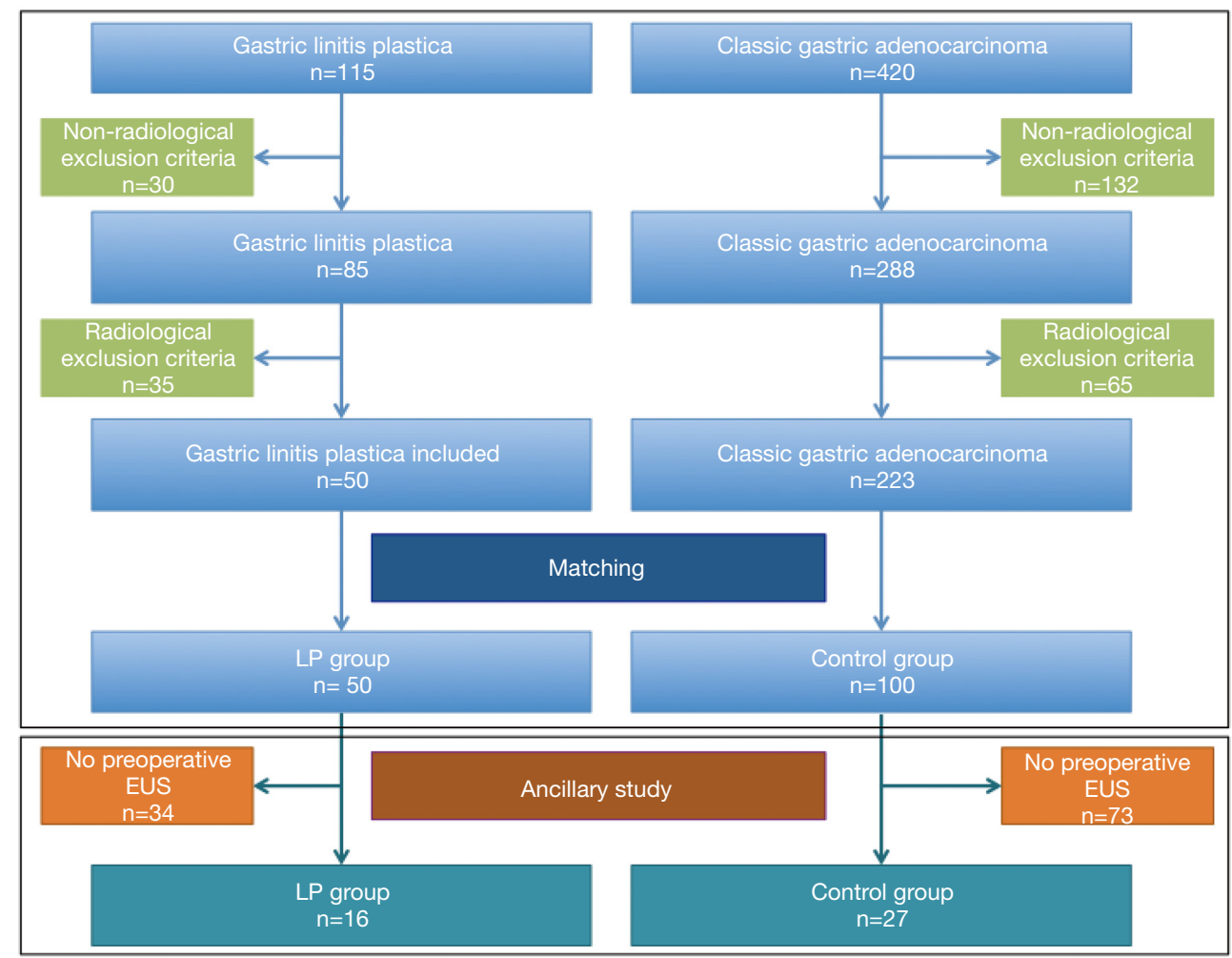

Figure 2 Flow chart.

fortuitous discovery of a gastric stromal tumor on the surgical specimen was not an exclusion criterion.

Finally, we established two groups: the LP group and the "classical" gastric carcinoma group (Control group). A flow chart is presented in Figure 2. All procedures performed in studies involving human participants were in accordance with the ethical standards of the institutional, and national research committee and with the 1964 Helsinki declaration and its later amendments. The Cochin Local Ethic Committee (ethics committee of our institution) approved the study (CLEP decision: AAA-2016-026001). Because of the retrospective nature of the research, the requirement for informed consent was waived.

\section{Definition of gastric LP}

All gastric LP were diagnosed on surgical piece of gastrectomy and defined by the existence of a main contingent of independent cells ( $>50 \%)$ and an abundant desmoplastic reaction. If the stromal reaction was not reported, the diagnosis was considered positive when endoscopic or ultrasound endoscopic appearance was characteristic with infiltrated/thickened/stiffened wall, diffuse or circumferential lesion and large folds that do not disappear on insufflation.

\section{EUS modalities}

We collected various data on EUS report: TNM stage, thickness of the wall, number and size of suspicious nodes, presence or not of ascites or peritoneal carcinomatosis.

\section{Statistical analysis}

The comparison of quantitative values was carried out using the Student test. The comparison of qualitative values was carried out using the Fisher test. The difference was considered significant with an alpha risk defined arbitrarily at $5 \%$.

\section{Results}

Sixteen and 27 patients were included in the LP and control groups in the study (Figure 2). Median age at diagnosis was 
Table 1 Characteristics of patients

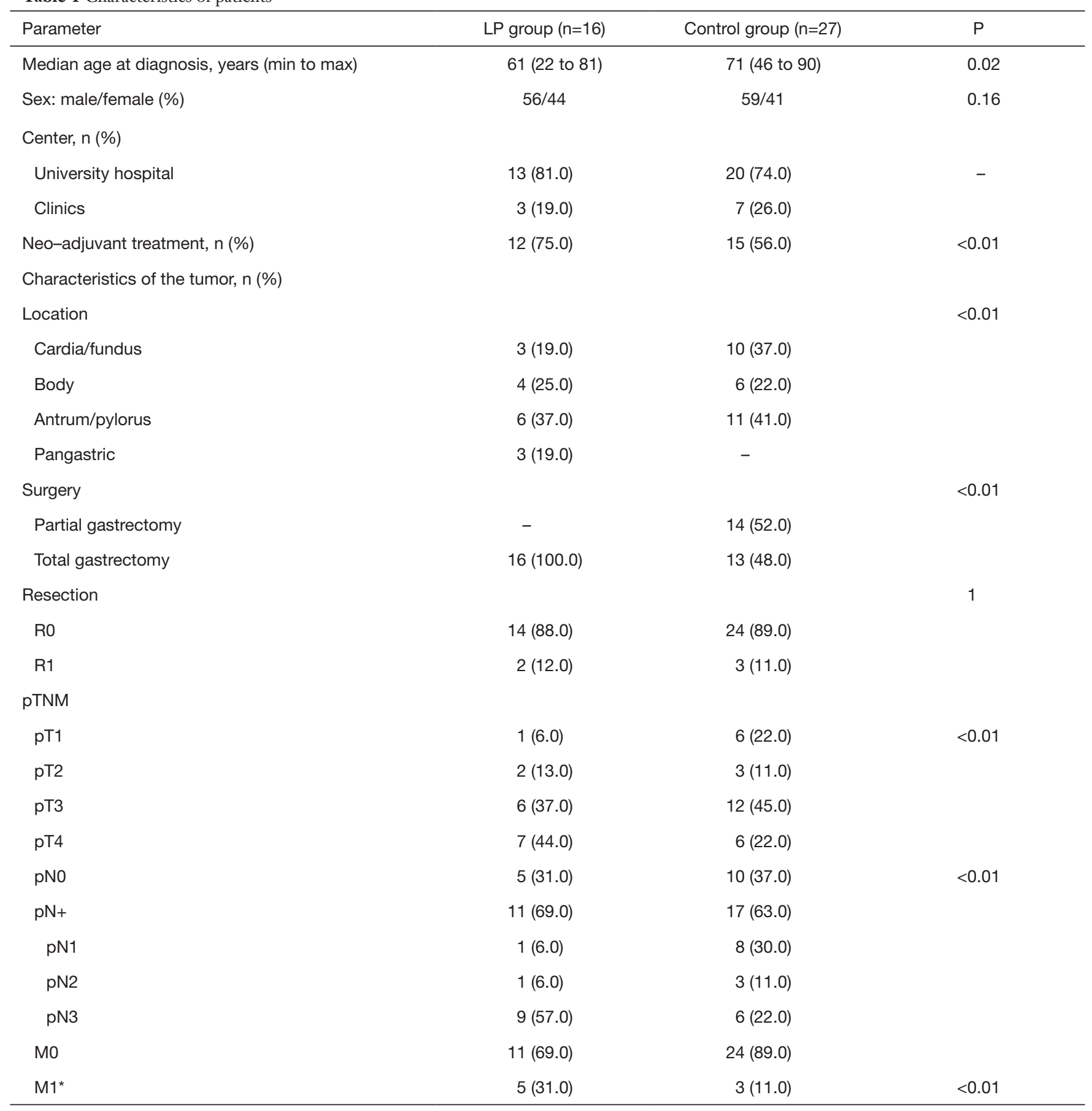

*, localized and resected peritoneal carcinomatosis.

61 and 71 years in the LP group and in the control group, respectively $(\mathrm{P}=0.02)$. Patients' characteristics are described in Table 1. No case of pan-gastric disease was reported in the control group vs. $19 \%$ in the LP group $(\mathrm{P}<0.01)$.
Cardial or fundic involvement was less frequent in the LP group than in the control group $(19 \%$ vs. $37 \%, \mathrm{P}<0.01)$. In the LP group, no patients with a histologic pT0-2 lesion were considered to have an advanced lesion usT3-4 on EUS 
Table 2 Correlation between endoscopic ultrasound and histological staging of parietal invasion in the LP group and in the control group

\begin{tabular}{|c|c|c|c|c|c|c|c|c|c|c|}
\hline \multirow{2}{*}{ EUS stage } & \multicolumn{10}{|c|}{ Histological stage } \\
\hline & $\mathrm{pT} 1$ & pT2 & pT3 & pT4 & Total & pT1 & pT2 & pT3 & pT4 & Total \\
\hline usT1 & - & - & - & - & 0 & 2 & - & - & - & 2 \\
\hline usT2 & 1 & 2 & 3 & - & 6 & 2 & 1 & 2 & - & 5 \\
\hline usT4 & - & - & - & - & 0 & - & - & - & 1 & 1 \\
\hline Total & 1 & 2 & 6 & 7 & 16 & 6 & 3 & 12 & 6 & 27 \\
\hline
\end{tabular}

LP, linitis plastica; EUS, endoscopic ultrasound.

Table 3 Predictive performance of endoscopic ultrasound in the staging of parietal and lymph node invasion in the LP group and in the control group

\begin{tabular}{lcc}
\hline Stage & LP group & Control group \\
\hline T (T0-2 vs. T3-4) & 77 & 89 \\
Sensibility & 100 & 56 \\
Specificity & 100 & 80 \\
Positive predictive value & 50 & 71 \\
Negative predictive value & & \\
N & 73 & 88 \\
Sensibility & 80 & 50 \\
Specificity & 89 & 75 \\
Positive predictive value & 57 & 71 \\
Negative predictive value & & \\
\hline
\end{tabular}

LP, linitis plastica; EUS, endoscopic ultrasound.

Table 4 Correlation between endoscopic ultrasound and histological staging of lymph node invasion in the LP group and control group

\begin{tabular}{|c|c|c|c|c|c|c|}
\hline \multirow{3}{*}{$\begin{array}{l}\text { EUS } \\
\text { staging }\end{array}$} & \multicolumn{6}{|c|}{ Histological stage } \\
\hline & \multicolumn{3}{|c|}{ LP group } & \multicolumn{3}{|c|}{ Control group } \\
\hline & $\mathrm{pNO}$ & $\mathrm{pN}+$ & Total & $\mathrm{pNO}$ & $\mathrm{pN}+$ & Total \\
\hline usNO & 4 & 3 & 7 & 5 & 2 & 7 \\
\hline usN+ & 1 & 8 & 9 & 5 & 15 & 20 \\
\hline Total & 5 & 11 & 16 & 10 & 17 & 27 \\
\hline
\end{tabular}

LP, linitis plastica; EUS, endoscopic ultrasound. whereas the proportion rose to $44 \%$ in the control group (Table 2). Sensitivity and specificity of preoperative EUS ability to identify an advanced wall involvement (usT3-4) were $77 \%$ and $100 \%$ in the LP group and $89 \%$ and $56 \%$ in the control group, respectively (Table 3).

Seventy-three per cent and $88 \%$ of patients with a histologic lymph node invasion $(\mathrm{pN}+)$ were considered with a EUS lymph node invasion (usN+) in the LP group and in the control group, respectively (Table 4). Sensitivity and specificity of preoperative EUS ability to identify a lymph node invasion were $73 \%$ and $80 \%$ respectively in the LP group and $88 \%$ and $50 \%$ respectively in the control group (Table 3). No patient with a histologic metastatic invasion $(\mathrm{pM}+)$ was identified as such with the EUS in the two groups.

\section{Discussion}

In the present study, we evaluated for the first time in a European LP population, the preoperative EUS performance. We found good sensitivities and specificities for evaluation of parietal involvement, respectively $77 \%$ and $100 \%$ in this population, compared to up to $89 \%$ and $56 \%$ in the control group of "classical" gastric carcinoma. For lymph node involvement sensitivities and specificities are also interesting, respectively $73 \%$ and $80 \%$ in the LP group and $88 \%$ and $50 \%$ in the control group. Our results are in line with the accuracy of EUS in LP published in a Chinese study, Shan et al. identified a $73 \%$ and $60 \%$ accuracy of EUS preoperative T- and N-staging, respectively (10). 
Of note, EUS had not caught up any diagnosis of peritoneal carcinomatosis ( 5 patients in LP group and 3 in control group). We identified non-inferior performance of the EUS between the two groups reinforcing the usefulness of EUS evaluation in all gastric adenocarcinoma, LP included. EUS allows guided and deep gastric biopsies if histological diagnosis of cancer could not be made by traditional endoscopy, which is common in LP, or lymph node biopsies when in doubt about the existence of lymph node invasion.

Our data are comparable to the literature. Kwee et al. (11) reported in a review of the literature a EUS performance in terms of sensitivity and specificity for assessing serosal involvement varying between $78 \%$ to $100 \%$ and $68 \%$ to $100 \%$ respectively in gastric cancer (GC). A Chinese study, on 15 patients operated for LP, reported a EUS diagnostic accuracy of $78 \%$ for T2 staging and $68 \%$ for T3 staging. In our study, we reported rates of $100 \%$ for T1-T2 staging and 77\% for T3-T4 staging in the LP group. Han et al. report significant higher risk of understaging the lesion in case of LP. In this study, $100 \%$ of pT4 lesions were classified usT3 and $50 \%$ of pT3 lesions were classified usT2 in the LP group and respectively $17 \%$ and $17 \%$ in the control group. EUS identifies well shallow and deep lesions but is, however, not effective enough to distinguish between $\mathrm{T} 1$ and $\mathrm{T} 2$ or T3 and T4 staging in the LP group.

In this study, we identified special characteristics of LP as a lower age at diagnosis, greater proportion of diffuse lesions and female (not significant) compared with "classical" GC. These characteristics are in line with published epidemiology of LP (12-14).

Only $60 \%$ of patients in LP group had EUS any time before surgery, whereas the French and European recommendations call for this examination in case of LP suspicion in order to define proximal (cardial involvement) and distal (pylorus or duodenal involvement) limits and perform guided biopsies when necessary. However, recommendations specify this should not delay treatment, and this may explain that not all patients had had this exam.

Our study presents some limitations considering that it was a retrospective analysis based on patients who received surgery. While on the one hand, the retrospective nature of the study allowed to confirm all patients included in the evaluated group, on the other hand, it resulted in an exclusion of $73 \%$ of cases identified as potential LP cases in the original study. Sixty percent of patients had EUS in the LP group but only $32 \%$ just before the surgery. Rate was similar in the control group (27\%) (Figure 2).

\section{Conclusions}

In conclusion, EUS appears as a helpful complementary exam to CT scan in the GC preoperative assessment. Our study identified for the first time a similar efficacy of EUS in gastric LP compared to "classical" gastric adenocarcinoma. Interestingly, two-thirds of patients failed to perform EUS before surgery in LP- and gastric carcinoma groups. Our study paves the way for the development of EUS before surgery in all types of gastric carcinoma.

\section{Acknowledgments}

Funding: None.

\section{Footnote}

Reporting Checklist: The authors present the study in accordance with the STROBE reporting checklist. Available at http://dx.doi.org/10.21037/atm-20-3474

Data Sharing Statement: Available at http://dx.doi. org/10.21037/atm-20-3474

Conflicts of Interest: All authors have completed the ICMJE uniform disclosure form (available at http://dx.doi. org/10.21037/atm-20-3474). All authors have no conflicts of interest to declare.

Ethical Statement: The authors are accountable for all aspects of the work in ensuring that questions related to the accuracy or integrity of any part of the work are appropriately investigated and resolved. All procedures performed in studies involving human participants were in accordance with the ethical standards of the institutional, and national research committee and with the 1964 Helsinki declaration and its later amendments. The Cochin Local Ethic Committee (ethics committee of our institution) approved the study (CLEP decision: AAA-2016-026001). Because of the retrospective nature of the research, the requirement for informed consent was waived.

Open Access Statement: This is an Open Access article distributed in accordance with the Creative Commons Attribution-NonCommercial-NoDerivs 4.0 International License (CC BY-NC-ND 4.0), which permits the noncommercial replication and distribution of the article with the strict proviso that no changes or edits are made and the 
original work is properly cited (including links to both the formal publication through the relevant DOI and the license). See: https://creativecommons.org/licenses/by-nc-nd/4.0/.

\section{References}

1. Ferlay J, Soerjomataram I, Dikshit R, et al. Cancer incidence and mortality worldwide: sources, methods and major patterns in GLOBOCAN 2012. Int J Cancer 2015;136:E359-86.

2. Siegel RL, Miller KD, Jemal A. Cancer statistics, 2016. CA Cancer J Clin 2016;66:7-30.

3. Binder-Foucard F, Bossard N, Delafosse P, et al. Cancer incidence and mortality in France over the 1980-2012 period: solid tumors. Rev Epidemiol Sante Publique 2014;62:95-108.

4. Agnes A, Estrella JS, Badgwell B. The significance of a nineteenth century definition in the era of genomics: linitis plastica. World J Surg Oncol 2017;15:123.

5. Coburn N, Seevaratnam R, Paszat L, et al. Optimal management of gastric cancer: results from an international RAND/UCLA expert panel. Ann Surg 2014;259:102-8.

6. Van Cutsem E, Dicato M, Geva R, et al. The diagnosis and management of gastric cancer: expert discussion and recommendations from the 12th ESMO/World Congress on Gastrointestinal Cancer, Barcelona, 2010. Ann Oncol 2011;22 Suppl 5:v1-9.

Cite this article as: Morgant S, Artru P, Oudjit A, Lourenco N, Pasquer A, Walter T, Gornet JM, Rouquette A, Brezault C, Coriat R. Endoscopic ultrasound efficacy in staging gastric linitis plastica lesion: a retrospective multicentric French study. Ann Transl Med 2021;9(1):50. doi: 10.21037/atm-20-3474
7. Cunningham D, Allum WH, Stenning SP, et al. Perioperative chemotherapy versus surgery alone for resectable gastroesophageal cancer. N Engl J Med 2006;355:11-20.

8. Morgant S, Artru P, Oudjit A, et al. Computed tomography scan efficacy in staging gastric linitis plastica lesion: a retrospective multicentric French study. Cancer Manag Res 2018;10:3825-31.

9. Washington K. 7th edition of the AJCC cancer staging manual: stomach. Ann Surg Oncol 2010;17:3077-9.

10. Shan G, Xu G, Li Y. Endoscopic ultrasonographic features of gastric linitis plastica in fifty-five Chinese patients. J Zhejiang Univ Sci B 2013;14:844-8.

11. Kwee RM, Kwee TC. Imaging in local staging of gastric cancer: a systematic review. J Clin Oncol 2007;25:2107-16.

12. Liu X, Cai H, Sheng W, et al. Clinicopathological Characteristics and Survival Outcomes of Primary Signet Ring Cell Carcinoma in the Stomach: Retrospective Analysis of Single Center Database. PLoS One 2015;10:e0144420.

13. Piessen G, Amielh D, Messager M, et al. Is pretreatment endoscopic biopsy a good predictor of signet ring cell histology in gastric carcinoma? World J Surg 2012;36:346-54.

14. Pernot $S$, Voron T, Perkins G, et al. Is signet-ring cell carcinoma a specific entity among gastric cancers? Gastric Cancer 2015;21:11428-38. 